\title{
Configurations and Control Strategy of a Single Stage Grid Connected PV System
}

\author{
K. Rajasekhara Reddy ${ }^{1 *}$, V.Nagabhaskar Reddy $^{2}$, M.Vijaya Kumar $^{3}$, Suresh Kumar Tummala ${ }^{4}$ \\ ${ }^{1}$ Research Scholar, JNTUA, Anantapuramu \& Assistant Professor, Department of EEE, Santhiram Engineering College, India \\ ${ }^{2}$ Professor \& Head, Department. of EEE, RGM College of Engg. \& Tech. Nandyal, India \\ ${ }^{3}$ Professor, Dept. of EEE \& Registrar, JNTUA,Ananthapuramu, India \\ ${ }^{4}$ Professor, Dept. of EEE, Gokaraju Rangaraju Institute of Engineering \& Technology, India
}

\begin{abstract}
In the grid-connected photovoltaic (PV) system, the array forms DC power. This generated power, a two-way grid process is called DC - DC - AC as a two-stage power conversion and, secondly, a DC-AC with a reduced circuit is called a single Stage Grid - Connected PV (SSGCPV) system. SSGCPV is more advantageous for reduced complexity, reliability and efficiency, in order to reduce the number of stepup transformer power with conventional inverter (or transformer) with less high PV voltage. This paper proposes a detailed review of the few configurations of the SSGCPV inverter system and also discusses its control strategy for tracking maximum power and generating pulses to obtain the required output power.
\end{abstract}

\section{Introduction}

In recent years, with increase in population and industrial sector the utilization of fossil fuels are increases drastically, but it would become global warming and air pollution. Therefore, all countries in the world concentrate on substitutes to fossil fuels and looking towards for renewable energy sources. The most abundantly available renewable sources are solar and wind, the wind-based power generation is not possible everywhere because of a constant of wind is not guaranteed[1]-[2]. Therefore, with day to day growth of technology the leading promising renewable source in power generation is photovoltaic (PV) system[3].

The PV system mainly used in stand-alone PV system and grid-connected PV system, in the past, the PV module cost is higher due to less productivity but nowadays increasing of productivity the cost becomes drop-down. Therefore, the grid-connected PV systems are widely preferred over than stand-alone systems[4]. In grid-connected PV system, an inverter is used to interface in between PV system and grid. An inverter generates required $\mathrm{AC}$ output voltage from $\mathrm{DC}$ input received from $\mathrm{PV}$ system while conventional inverter produces two-level of the output voltage and have few issues while in conversion processes such as higher harmonic distortion, switching frequency, $d v / d t$ stress and filter requirement is more significant at output side due to which cost is increased[5]-[6].Multilevel Inverter (MLI) plays a vital role in renewable energy applications to produce the desired output ac voltage which increases efficiency, decreasing harmonics, and reduced losses. However, in basic MLIs number of components and switches required are more but due to the advancement of technology MLIs are developed with reduced components[7] and switches which decreases filter requirement at output side and switching harmonics as compared with a two-level inverter[8]-[10].

In general, grid-connected PV inverters mainly classified as (according to PV module configuration) the central inverter, string inverter, multi-string and moduleintegrated inverter as shown[11] in Fig.1. The central inverter connected to three phase interconnection with large power application such as power plants and commercial, i.e. more than $10 \mathrm{~kW}$ while other inverters called string and multi strings are connected with single or three phase and used in residential and commercial applications. Finally, module inverter is used small power applications less than $300 \mathrm{~W}$ and interconnected with single-phase systems[12], [13].

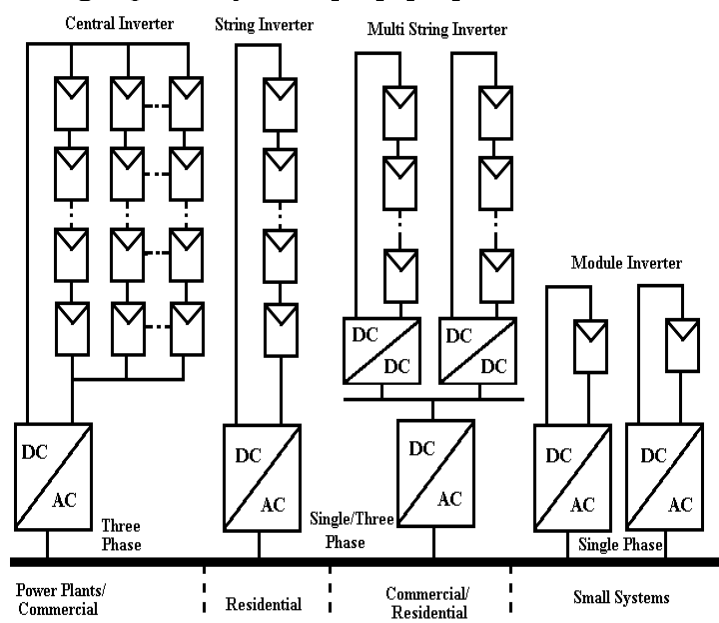

Fig.1. Grid-connected PV Inverters[11]

\footnotetext{
* Corresponding author raju.gprec@gmail.com
} 
The power processing in between PV system and a grid plays a key role, conventionally multi stage power processing, i.e. DC-DC-AC is widely used in gridconnected PV system. Therefore, with the addition of the power converter in power processing, increases cost and low efficiency. This paper describes the different singlestage power processing configurations with its control strategies in grid-connected PV system[14], [15].

\section{Single Stage Configurations}

The sunlight into DC with the help of PV array and is then convert into $\mathrm{AC}$, and it injects into the grid, the output of the PV system depends on temperature and solar irradiation. Based on the power processing stages PV inverters are classified into two types as multi-stage inverters and single-stage inverter[16]-[19]. In gridconnected PV system, conventional multi-stage inverters employ more than one power processing stages, in which the task of one or many stages performs boosting the DC output from PV system and final stage being conversion of the boosted DC into desired AC output. Nevertheless, most of the PV inverters interfaced with a two-stage power conversion process as shown in Fig.2.During the first stage, the output of the PV array has amplified the voltage to a higher level by using a boost converter while tracking the maximum power[20]. Such two-stage PV inverters are working well, but due to the increase of many power conversions have drawbacks as a bigger size, higher cost, low reliability and lower efficiency. The help of single-stage PV inverter overcomes the drawbacks as mentioned earlier[21].

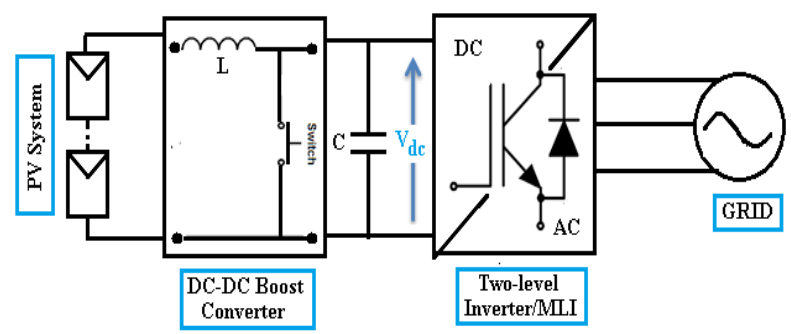

Fig.2. Two-Stage grid connected PV Inverter

In Single-stage PV Inversion, the numbers of power processing stages are deduced and are direct converts DC to AC and integrate into the grid system. This in turn provides less size, less cost and complexity. It is also easy to incorporate the maximum power tracking technique (MPPT) to track the maximum power from the all environmental conditions. The schematic structure of the single-stage grid-connected PV system (SSGCPV) as shown in Fig.3, it includes PV array to convert sunlight into DC, MPPT to track the maximum power from PV system and dc link capacitor that connect in between PV array and three phase VSI inverter. Also the control scheme of an inverter, RL filter connected the grid[22][24].

Fig.3. is a structure of SSGCPV, in which voltage amplification not included. According to voltage amplification, SSGCPV inverter systems are categorized into three types as a step up transformer, PV array, and Inherent Boost inverter systems[21].

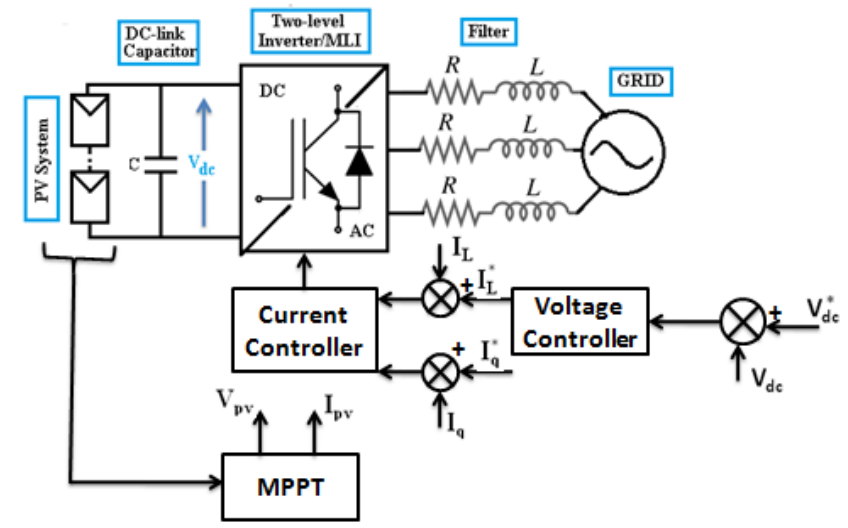

Fig.3. Schematic structure of SSGCPV inverter

\section{A. Step-up Transformer SSGCPV invertert system}

Step-up Transformer SSGCPV inverter as shown in Fig.4, in this configuration step-up transformer placed at the output terminals of the three-phase inverter, the voltage amplification is obtained after inverting DC into AC, after amplification of voltage secondary of transformer fed to the grid. This type of configuration suffers with drawback by addition of transformer, will add the bulk and cost of the complete system.

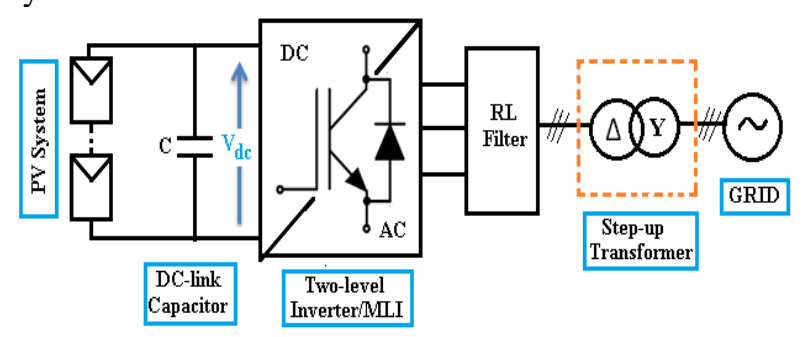

Fig.4. Step-up Transformer SSGCPV inverter system

\section{B. PV-ARRAY SSGCPV inverter system}

The voltage amplification, the number of PV modules increases and connected in series to frame as a PV array, as shown in Fig.5, at the input it generates the DC power, as per the requirement of the grid, and is directly fed to an inverter through the DC-link capacitor. The merit of this type of configuration is no need to use the step-up transformer. Therefore, it avoids synchronization problem at the output of an inverter. It suffers from the following demerits such as hot spots during the partial shading, leakage current probability increases, and reduced safety.

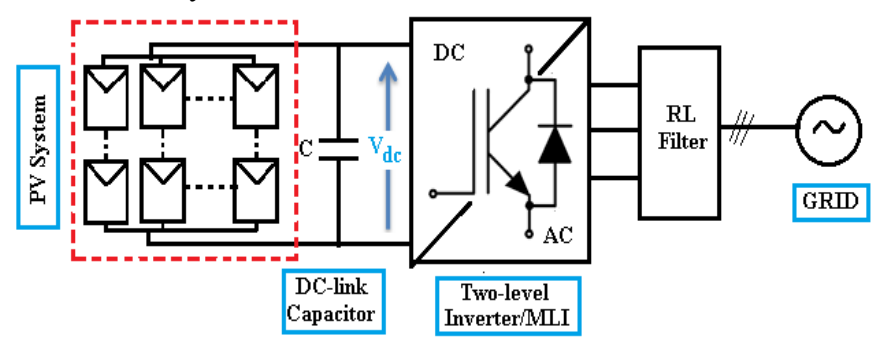

Fig.5. PV-Array SSGCPV inverter system

\section{Inherent boost SSGCPV inverter systems}

This system with single power electronic stage attains the following functions, namely, it tracks the maximum 
power from MPPT, voltage amplification, and inversion as shown in Fig.6. The principal advantages of this configuration are compact in size, high reliability, more performance, and lesser weight and cost. If the number power stages are lesser, it is easy to integrate with modules. The main drawback of this system is the design of the control circuit is somewhat complicated if MLIs with boosting is incorporated in the single stage conversion[25]-[27].

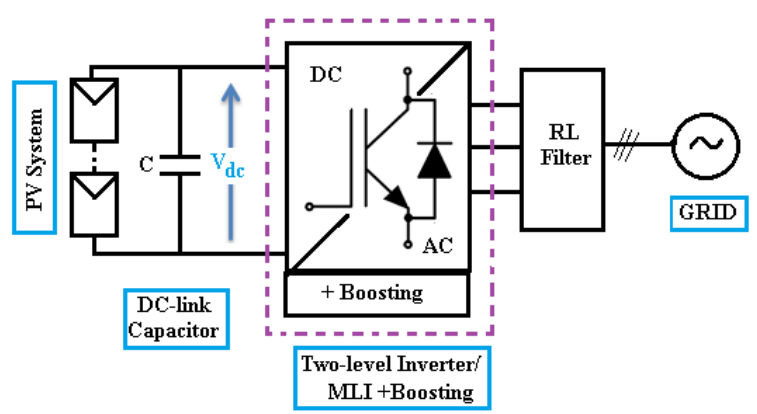

Fig.6. Inherent boost SSGCPV inverter systems

\section{Control Strategy of Single Stage Inverter}

The equivalent circuit, output voltage and current relationship of PV module is expressed in[28]. The essential device in SSGCPV system is an inverter. The single stage inverter control strategy is depicted in the Fig.7. The control circuit is divided into two control loops named as an inner current loop for controlling duty ratio and outer voltage loop to track the maximum power point[29], [30] (MPP) to stabilize the dc-link voltage. Two currents are involved in inner loop control one is active current $\left(I_{d}\right)$ and reactive current $\left(I_{q}\right)$. In normal operation, the output of the voltage loop (active current $\left(\mathrm{I}_{\mathrm{dr}}\right)$ ) used as a reference while reference of reactive current $\left(\mathrm{I}_{\mathrm{qr}}=0\right)$ makes it as zero. Therefore, SSGCPV inverter operates at a nearly unity power factor. To control the grid current and dc-link voltage typical PI controllers are utilized. The feedforward control strategy is adopted for easy control of active and reactive currents[31].

The design of the phased locked loop (PLL) is essential for synchronizing phase angle and grid voltage, which is based on synchronous (d-q) reference frame. For the generation of inverter switching pulses, it is necessary to produce active reference and the reactive reference voltage are from the inner loop, and these are transformed into $\mathrm{V}_{\mathrm{dq}}$ to $\mathrm{V}_{\mathrm{abc}}$. The obtained $\mathrm{V}_{\mathrm{abc}}$ is applied to PWM generator to produce required switching pulses to an inverter[32].
The mathematical modeling of three phase grid connected PV system as follows for conventional inverter model

$$
\begin{aligned}
& V_{a i}=R i_{a i}+L \frac{d i_{a i}}{d t}+e_{g a} \\
& V_{b i}=R i_{b i}+L \frac{d i_{b i}}{d t}+e_{g b} \\
& V_{a i}=R i_{c i}+L \frac{d i_{a i}}{d t}+e_{g c}
\end{aligned}
$$

Where " $V_{a i}, V_{b i}, V_{c i}$ ", " $i_{a i}, i_{b i}, i_{c i}$ ", and " $e_{g a}, e_{g b}, e_{g c}$ " are the inverter voltages, inverter currents and grid voltages. The equation (1) can be written in state space form as,

$$
\begin{aligned}
& i_{a i}=-\frac{R}{L} i_{a i}-\frac{1}{L} e_{g a}+\frac{1}{L} V_{a i} \\
& i_{b i}=-\frac{R}{L} i_{b i}-\frac{1}{L} e_{g b}+\frac{1}{L} V_{b i} \\
& i_{c i}=-\frac{R}{L} i_{c i}-\frac{1}{L} e_{g e}+\frac{1}{L} V_{c i}
\end{aligned}
$$

Equation (2) is a time-varying model and is converted into time-invariant by the rotational transformation. The mathematical model at the line frequency can be obtained as:

$$
\begin{aligned}
& \dot{I}_{d}=-\frac{R}{L} I_{d}+\omega I_{q}-\frac{E_{d d}}{L}+\frac{V_{d}}{L} \\
& \dot{I}_{q}=-\omega I_{d}-\frac{R}{L} I_{q}-\frac{E_{q}}{L}+\frac{V_{q}}{L}
\end{aligned}
$$

The active and reactive power calculations at the grid side in state space form as:

$$
\begin{aligned}
& P=\frac{3}{2}\left(E_{g d} I_{d}+E_{d q} I_{q}\right) \\
& Q=-\frac{3}{2}\left(E_{g d} I_{q}+E_{d q} I_{d}\right)
\end{aligned}
$$

Where, " $E_{g d}, I_{d}$ " and " $E_{d q}, I_{d}$ " are the voltages and currents along with $\mathrm{d}$ axis and $\mathrm{q}$ axis in $\mathrm{d}-\mathrm{q}$ synchronous frame. In normal operating mode the power factor become unity, then the voltage $\mathrm{E}_{\mathrm{dq}}$ is zero. Therefore, the active and reactive power as[32], [33],

$$
\begin{aligned}
& P=\frac{3}{2} E_{g d} I_{d d} \\
& Q= \\
& -\frac{3}{2} E_{g d} I_{q}
\end{aligned}
$$




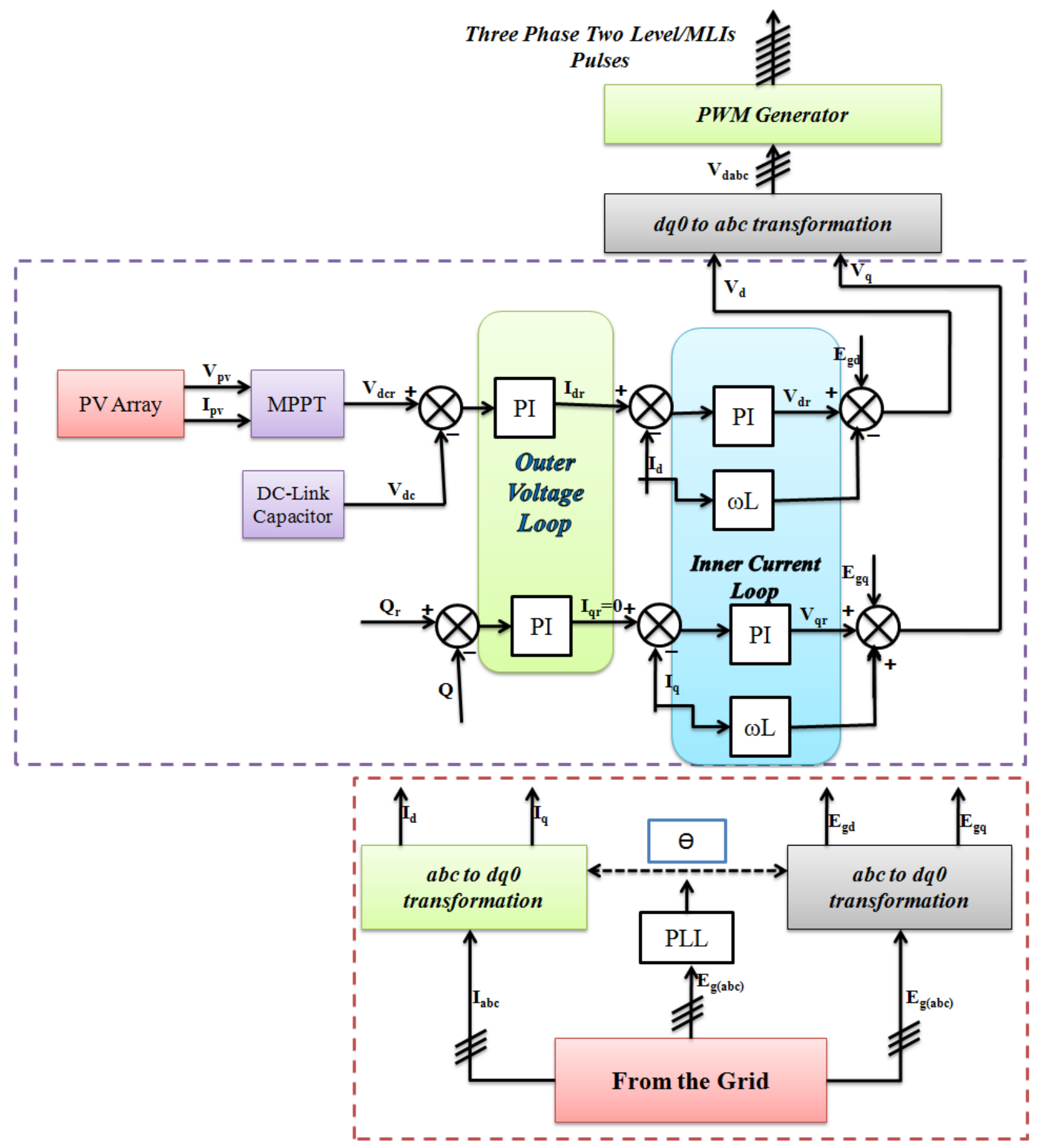

Fig.7. Control strategy of SSGCPV inverter system

In Fig.7, the inner loop control plays a key role in a control strategy of an inverter to deliver the maximum power to the grid. If linear controllers are used in an inner current loop, however, these linear controllers have some boundary limitations. Therefore these are not delivering the desired power to the grid because PV system is non linear unit and the input is completely depending upon environmental conditions. The best choice for controlling the nonlinear systems is the nonlinear controller named as robust controllers. The design of robust controllers is also possible for SSGCPV systems to generate the required control singles for controlling and delivering maximum power to the grid even though at any uncertainties[34].

\section{Conclusion}

A brief review in SSGCPV systems is discussed in this paper. Nowadays grid-connected PV systems are plays a vital role in the generation of power while the demand is increasing, in these systems, an inverter is a heart of the system and is divided into multi-stage with and SingleStage Systems (SSS). In the first chapter discussed with advantages of the solar energy, basic idea about the generalized grid-connected types of an inverter and briefly about single stage system is introduced. The

\footnotetext{
* Corresponding author raju.gprec@gmail.com
} 
second section has discussed the merits of SSS, and their different configurations also discussed the advantages and disadvantages of each configuration which uses to researchers to select kind of layout as per their requirements. The third section is considered as a control strategy of SSGCPV inverter, given a clarity over this strategy how to track the maximum power and how to deliver the maximum power to the grid. In the future, MLI is come into the SSS to improve the reliability, efficiency and reduced filter utilization.

\section{References}

1. I. Hussain, M. Kandpal, and B. Singh, "Electrical Power and Energy Systems Grid integration of single stage SPV-STATCOM using cascaded 7level VSC," Int. J. Electr. Power Energy Syst., vol. 93, pp. 238-252, 2017.

2. P. Kala and S. Arora, "A comprehensive study of classical and hybrid multilevel inverter topologies for renewable energy applications," Renew. Sustain. Energy Rev., vol. 76, no. December 2016, pp. 905-931, 2017.

3. S. Chaudhary, Z. Ahmad, and S. N. Singh, "Inverters: A Review," 2018 Natl. Power Eng. Conf., pp. 1-6, 2018.

4. B. Yang, T. Yu, H. Shu, D. Zhu, N. An, Y. Sang, and L. Jiang, "Control Engineering Practice Perturbation observer based fractional-order sliding-mode controller for MPPT of gridconnected PV inverters: Design and real-time implementation," vol. 79, no. July, pp. 105-125, 2018.

5. S. H. Shehadeh, S. Ieee, H. H. Aly, M. Ieee, and F. Ieee, "Photovoltaic Multi-level Inverters Technology," vol. 2, pp. 648-655, 2015.

6. J. Venkataramanaiah, Y. Suresh, and A. Kumar, "A review on symmetric, asymmetric , hybrid and single DC sources based multilevel inverter topologies," Renew. Sustain. Energy Rev., vol. 76, no. July 2016, pp. 788-812, 2017.

7. K. K. Gupta and S. Jain, Control of Multilevel Inverters With Reduced Device Count. Elsevier Inc., 2018.

8. A. Nami and H. Nademi, Modular Multilevel Converter ( $M M C$ ) and Its Control, no. Mmc. Elsevier Inc., 2018.

9. C. Luo, M. Su, X. Hou, H. Han, Y. Sun, and Y. Yang, "Stage PV Inverters for Grid-connected Applications," 2018 IEEE Innov. Smart Grid Technol. - Asia (ISGT Asia), vol. 1, no. d, pp. 622627.

10. J. Singh, R. Dahiya, and L. M. Saini, "Recent research on transformer based single DC source multilevel inverter: A review," Renew. Sustain. Energy Rev., no. May, pp. 1-18, 2017.

11. M. Barghi and A. Teke, "Investigation of multilevel multifunctional grid connected inverter topologies and control strategies used in photovoltaic systems," Renew. Sustain. Energy Rev., vol. 42, pp. 361-376, 2015.
12. J. Jana, H. Saha, and K. Das Bhattacharya, "A review of inverter topologies for single-phase gridconnected photovoltaic systems," Renew. Sustain. Energy Rev., vol. 72, no. August 2016, pp. 12561270, 2017.

13. S. Z. M. Noor, M. Ieee, A. M. Omar, N. N. Mahzan, I. R. Ibrahim, U. Teknologi, M. Uitm, and S. Alam, "A Review of Single-Phase Single Stage Inverter Topologies for Photovoltaic System," pp. 19-20, 2013.

14. C. Sciences, "Design and operation of a multifunction photovoltaic power system with shunt active filtering using a single-stage threephase multilevel inverter," pp. 1412-1425, 2017.

15. Rajagiri A, MN Sandhya, Nawaz S, Suresh Kumar T, E3S Web of Conferences 8701004 (2019).

16. B. S. Prasad, S. Jain, V. Agarwal, and S. Member, "Universal Single-Stage Grid-Connected Inverter," vol. 23, no. 1, pp. 128-137, 2008.

17. N. S. S. Multistring and M. Inverter, "NewlyConstructed Simplified Single-Phase Multistring Multilevel Inverter Topology for Distributed Energy Resources," vol. 26, no. 9, pp. 2386-2392, 2011.

18. H. Patel, V. Agarwal, and S. Member, "A SingleStage Single-Phase Transformer-Less," vol. 24, no. 1, pp. 93-101, 2009.

19. S. B. Kjaer, J. K. Pedersen, S. Member, and F. Blaabjerg, "A Review of Single-Phase GridConnected Inverters for Photovoltaic Modules," vol. 41, no. 5, pp. 1292-1306, 2005.

20. D. Chen, S. Member, J. Jiang, Y. Qiu, J. Zhang, and F. Huang, "Single-Stage Three-Phase CurrentSource," vol. 32, no. 10, pp. 7591-7601, 2017.

21. S. Jain, V. Agarwal, and S. Member, "A SingleStage Grid Connected Inverter Topology for Solar PV Systems With Maximum Power Point Tracking," vol. 22, no. 5, pp. 1928-1940, 2007.

22. S. S. Lee, "Single-Stage Switched-Capacitor Module $\left(\mathrm{S}^{3} \mathrm{CM}\right)$ Topology for Cascaded Multilevel Inverter," IEEE Trans. Power Electron., vol. 33, no. 10, pp. 8204-8207, 2018.

23. M. Nguyen and T. Tran, "A Single-Phase SingleStage Switched-Boost Inverter," vol. 33, no. 8, pp. 6769-6781, 2018.

24. Yogeswara Reddy B, Srinivas Rao J, Suresh Kumar $\mathrm{T}$, Nagarjuna A, International Journal of Innovative Technology and Exploring Engineering, 8(11), 1194-1198, 2019M. Nguyen and T. Tran, "Transactions on Power Electronics," vol. 8993, no. c, 2017.

25. S. K. Sahoo, S. Sukchai, and F. F. Yanine, "Review and comparative study of single-stage inverters for a PV system," Renew. Sustain. Energy Rev., vol. 91, no. April, pp. 962-986, 2018.

26. M. Khodabandeh, S. Member, E. Afshari, and S. Member, "Transactions on Power Electronics A Single-Stage Soft-Switching High-Frequency ACLink PV Inverter: Design, Analysis , and Evaluation of Si-based and SiC-based Prototypes," IEEE Trans. Power Electron., vol. PP, no. c, p. 1, 2018. 
27. M. A. Mahmud, H. R. Pota, M. J. Hossain, S. Member, and N. K. Roy, "Robust Partial Feedback Linearizing Stabilization Scheme for Three-Phase Grid-Connected Photovoltaic Systems," vol. 4, no. 1, pp. 423-431, 2014.

28. A. Dannier, M. Coppola, and P. Guerriero, "Enhanced MPPT algorithm for Multilevel PV Inverter," 2018 Int. Symp. Power Electron. Electr. Drives, Autom. Motion, pp. 847-852, 2018.

29. M. T. Azari, M. Sabahi, E. Babaei, and S. Member, "Modified Single-Phase Single-Stage Grid- tied Flying Inductor Inverter with MPPT and Suppressed Leakage Current," vol. 0046, no. c, 2017.

30. Y. Shi, B. Liu, and S. Duan, "Modelling, control and performance analysis of a single-stage singlephase inverter with reduced low-frequency input current ripple," 2018.

31. A. Q. Al-shetwi, M. Zahim, and F. Blaabjerg, "Low voltage ride-through capability control for singlestage inverter-based grid-connected photovoltaic power plant," Sol. Energy, vol. 159, no. November 2017, pp. 665-681, 2018.

32. Suresh Kumar Tummala, Dhasharatha G, E3S Web of Conferences 87, 01030 (2019)

33. M. A. Mahmud, M. J. Hossain, S. Member, H. R. Pota, and N. K. Roy, "Robust Nonlinear Controller Design for Three-Phase Grid-Connected Photovoltaic Systems Under Structured Uncertainties," vol. 29, no. 3, pp. 1221-1230, 2014. 